\title{
Effectiveness of interventions to reduce flour dust exposures in supermarket bakeries in South Africa
}

\author{
Roslynn Baatjies, ${ }^{1,2}$ Tim Meijster, $^{3}$ Dick Heederik, ${ }^{3}$ Ingrid Sander, ${ }^{4}$ \\ Mohamed F Jeebhay ${ }^{2}$
}

- Additional material is published online only. To view please visit the journal online (http://dx.doi.org/10.1136/ oemed-2013-101971).

${ }^{1}$ Department of Environmental and Occupational Studies, Faculty of Applied Sciences, Cape Peninsula University of Technology, Cape Town, South Africa

${ }^{2}$ Centre for Occupational and Environmental Health Research, School of Public Health and Family Medicine, University of Cape Town, Cape Town,

South Africa

${ }^{3}$ Division of Environmental Epidemiology, Institute for Risk Assessment Sciences, Utrecht University, Utrecht,

The Netherlands

${ }^{4}$ Institute for Prevention and Occupational Medicine of the German Social Accident Insurance (IPA), Ruhr-University Bochum, Germany, Germany

\section{Correspondence to}

Professor Mohamed F Jeebhay, Centre for Occupational and Environmental Health Research, School of Public Health and Family Medicine, University of

Cape Town, Room 4.47, Fourth Level, Falmouth Building, Anzio Road, Observatory, Cape Town 7925 South Africa;

mailto:Mohamed.Jeebhay@uct. ac.za

Received 6 November 2013 Revised 29 April 2014 Accepted 15 May 2014 Published Online First 4 June 2014

\section{SLinked}

- http://dx.doi.org/10.1136/ oemed-2014-102389

CrossMark

To cite: Baatjies $R_{\text {, }}$

Meijster T, Heederik D, et al.

Occup Environ Med

2014;71:811-818.

\section{ABSTRACT}

Rationale A recent study of supermarket bakery workers in South Africa demonstrated that $25 \%$ of workers were sensitised to flour allergens and $13 \%$ had baker's asthma. Evidence on exposure reduction strategies using specifically designed interventions aimed at reducing the risk of baker's asthma is scarce.

Objectives The aim of this study was to evaluate the effectiveness of different control measures to reduce airborne flour dust exposure using a randomised design. Methods A group-randomised study design was used to assign 30 bakeries of a large supermarket chain store to two intervention groups and a control group, of which 15 bakeries were studied. Full-shift environmental personal samples were used to characterise exposure to flour dust and wheat and rye allergens levels

pre-intervention $(n=176)$ and post-intervention $(n=208)$. Results The overall intervention effect revealed a 50\% decrease in mean flour dust, wheat and rye allergen exposure. The reduction in exposure was highest for managers $(67 \%)$ and bakers $(47 \%)$, and lowest for counterhands (23\%). For bakers, the greatest reduction in flour dust was associated with control measures such as the use of the mixer lid $(67 \%)$, divider oil $(63 \%)$ or focused training $(54 \%)$. However, the greatest reduction $(80 \%)$ was observed when using a combination of all control measures.

Conclusions A specially designed intervention strategy reduced both flour dust and allergen levels. Best results were observed when combining both engineering controls and training. Further studies will investigate the long-term health impact of these interventions on reducing the disease burden among this group of bakers.

\section{INTRODUCTION}

The burden of occupational allergic respiratory disease due to airborne flour dust and bakery enzymes has been well documented ${ }^{1}$ and is a major contributor to occupational allergic respiratory disease among food processing workers. In several earlier studies on bakery workers, $10 \%-28 \%$ of workers were sensitised to cereal flour allergens, while the prevalence of baker's asthma was reported to be between $5 \%$ and $17 \% \cdot{ }^{2-7} \mathrm{~A}$ third of workers with occupational asthma are unemployed up to 6 years after diagnosis. ${ }^{8}{ }^{9}$ Exposure-response studies have demonstrated a clear relationship between exposure to flour and bakery enzymes and specific sensitisation or occupational asthma. ${ }^{6}$ 10-12 There is evidence indicating that substantial reduction in exposure will lead to a measurable

\section{What this paper adds}

- Few studies have reported the effect of exposure reduction strategies that use specifically designed targeted interventions aimed at reducing the risk of baker's asthma and bakeries in particular.

- This is the first group-randomised intervention study conducted in supermarket bakeries.

- Flour dust exposure data are used to evaluate the individual and combined effect of control measures specifically designed for reducing airborne flour dust and allergen exposures.

- This study demonstrated that a specially designed intervention strategy tailored to this setting was extremely effective in reducing airborne flour dust and allergen.

- A multi-pronged strategy that combined engineering and improved work practices through training was most effective.

reduction in disease burden. ${ }^{13-15}$ While there have been some notable successes in reducing occupational asthma especially from latex in healthcare workers, ${ }^{16}$ for most other allergens only few studies are available. Flour dust allergens levels show no decrease over the last decade. ${ }^{17} 18$ Several dose-response studies indicate that exposure levels will need to be reduced by around 10 -fold to have a significant impact on sensitisation and disease rates related to exposure to flour and enzymes. ${ }^{12} 19$

This highlights the need for effective interventions to reduce the incidence of occupational respiratory disease related to occupational flour dust exposure. ${ }^{20}$ Prevention of occupational asthma related to work-sensitising agents can be achieved by measures such as substitution of the causal agent (s) or reduction of the occupational exposures. ${ }^{21}$ However, in the same publication it was explicitly noted that few studies exist on the effect of systematic interventions. While total avoidance is not possible in bakeries, exposure reduction is the preferred approach.

Well designed intervention studies with detailed exposure characterisation to determine the effect of exposure reductions for occupational asthma are few. ${ }^{20}$ Few studies are available that describe the effectiveness of interventions specifically in bakeries. This study presents the follow-up exposure results of a larger intervention study incorporating 
both exposure assessment and health outcome components. The aim was to evaluate the effectiveness of intervention strategies introduced within instore bakeries of supermarkets for improved flour dust control.

\section{METHODS}

\section{Study design}

The study employed a group-randomised design, particularly useful to evaluate interventions on a group level for example when workers are sharing a work site. ${ }^{22}$ Bakeries were randomly assigned to an intervention as outlined in online supplementary figure S1 and were divided randomly into three equal groups taking into consideration the size of the bakery and number of workers in each bakery.

\section{Study population}

Environmental exposure of 18 bakeries that were previously assessed in the baseline exposure assessment study ${ }^{23}$ were re-evaluated following implementation of the intervention. Bakeries were stratified into small, medium and large size based on the number of workers employed and the production output (bread, rolls, cakes) of the bakery. Supermarket bakeries had an average workforce of 20 workers per bakery (range 6-42) with an average production output of approximately 10000 bakery units per week per bakery (range 4360-18 346). The bakery size indices were derived using tertile values of the following variables as cut-off points-number of employees: $\leq 14,15-21$ and $>21$ and production output in units per week: $\leq 7504$, 7505-10 868 and >10 868. A number of bakeries were randomly selected from each stratum for more detailed investigation. $^{23}$

In this post-intervention assessment, three bakeries from the control group were lost to follow-up for various reasons (eg, closure), and consequently a lower number of samples were obtained from the control group.

\section{Intervention development}

Information obtained from the baseline study on determinants associated with high flour dust exposure and compliance with preventive measures was evaluated by the research team. This was accompanied by input from a multidisciplinary team of bakery workers, managers and engineers from the chain stores to inform the final intervention strategies that were developed and implemented. Information was available from the baseline study on presence and type of ventilation system, use of personal protective equipment, education and training activities, and number of mixing tubs in each bakery. Furthermore, various work practices were identified during dough preparation (shaking of bags, enclosure of mixing tubs, use of divider oil vs sprinkling with flour for dough processing), and cleaning of the bakery at individual level. Through focused group discussions with stakeholders, two specific intervention strategies were developed that incorporated engineering, administrative and behavioural components.

\section{Intervention element 1: redesigned lid for mixer tub}

The evaluation indicated that use of mixer tubs were associated with high (peak) exposures (dumping of flour, mixing of products) (figure 1A). Therefore, the first element of the intervention involved redesigning/refitting of the lid of the mixers tubs by introduction of a specialised lid with an inlet to prevent spillage of flour during dumping/emptying of flour from bags and when the mixer tub was operated at high speeds (Macadams South Africa) (figure 1B).

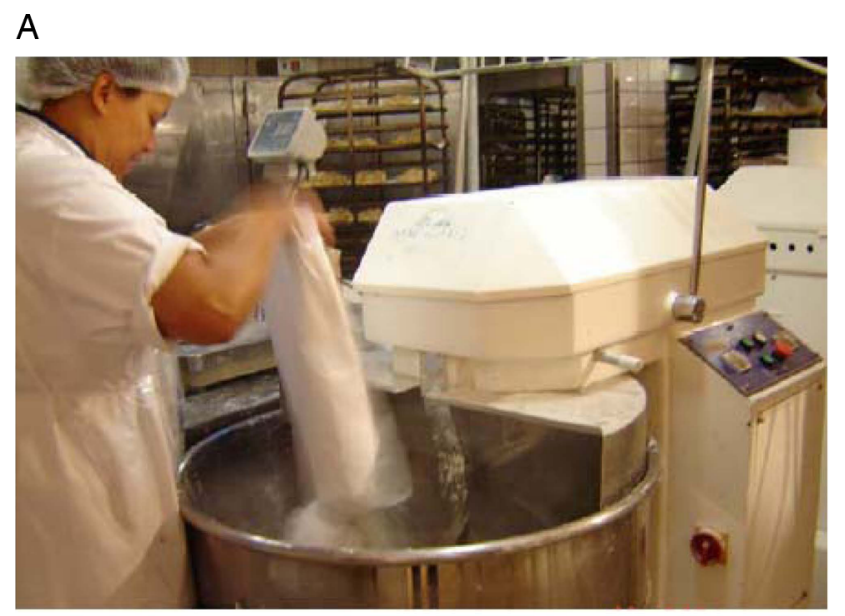

B

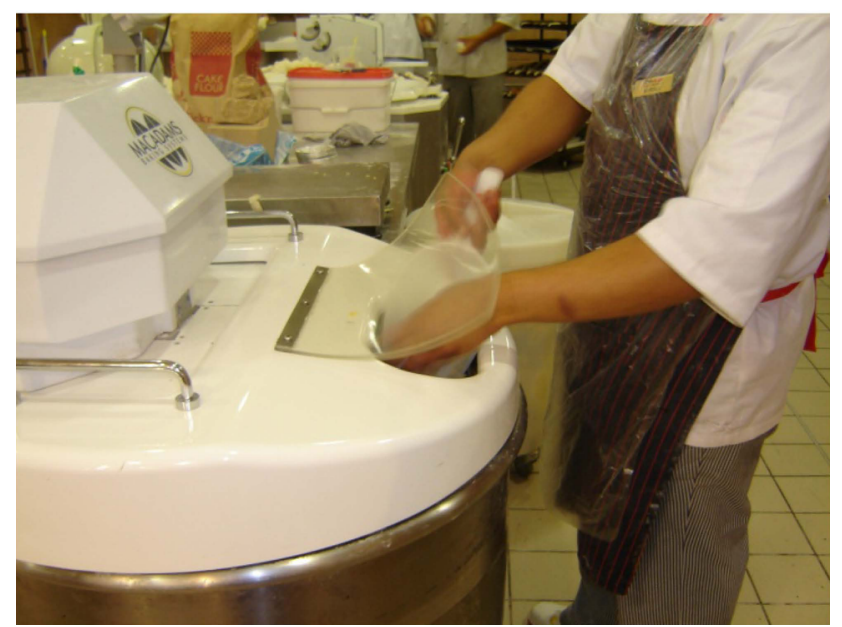

Figure 1 (A) Mixer tub with no lid, creating high dust exposures during dough mixing processes (adding flour to mixer). (B) Redesigned mixer tub lid, with inlet to reduce flour dust exposure.

Intervention element 2: dust control training

The second element of the intervention focused on training of workers to improve awareness regarding the health risks associated with exposure to flour dust and following safer handling of flour and modified work procedures based on a similar approach developed for bakery workers in the Netherlands. ${ }^{i}$ ii The training focused on work practices and covered the following dust reduction elements:

- Work practices: careful handling of bags when dumping/ emptying into the mixer tub during dough making (no shaking)

- Process controls: using divider oils, rubbing flour or using a sieve for dusting dough table (instead of flour sprinkling) during dough processing

- Hygiene procedures: using one the following options instead of dry sweeping with a normal bristle broom:

- An industrial vacuum cleaner with a high efficiency particulate air filter (Ghilbli AS 590, Supplier, Tennant) and wet methods

- A rubber broom or microfibre mop

\footnotetext{
${ }^{\mathrm{i}}$ http://www.blijmetstofvrij.nl/images/2011-05/handboek-stofvrij.pdf

ii http://www.oehru.uct.ac.za/docs/BAKERY\%20DUST\%20BOOKLET\% 20A5(final).pdf
} 
- Personal protective equipment: using respirators (Model 8822 respirators, FFP2, supplier 3M) during short-term dusty tasks such as mixing flour ingredients in a mixer tub without a lid.

The training programme was supplemented by the provision of technical aids such as vacuum cleaners, microfibre/rubber mops and respirators. Furthermore, posters on specific dust reduction elements were also provided and mounted on bakery walls to reinforce the information provided in the training manual. The training programme was directed at all workers with attention to specific tasks and work practices for reducing exposure to flour dust. A training video was developed to train all food handlers, illustrating sources of high flour dust exposures and control measures to be followed to reduce these exposures. An intensive training programme for all managers and bakers in the stores was then undertaken by the research team. Training was conducted onsite in each bakery store. The training included a brief overview of the study, followed by the video presentation. That was followed by a discussion and a question and answer session. The training also included a demonstration on the correct use of the industrial vacuum cleaner.

\section{Intervention implementation}

The intervention study undertaken had two interventions arms (see online supplementary figure S1):

- Group 1, Lid for mixer tub and dust control training: the first group of 10 bakeries was assigned with a re-designed lid for the mixer tub in addition to being supplied with the flour dust control training manual accompanied by training workshops on its use. Each bakery was also provided with an industrial vacuum cleaner.

- Group 2, Dust control training only: the second group of 10 bakeries was assigned only with the dust control training manual accompanied by training workshops on its use. Each bakery was also provided with an industrial vacuum cleaner.

- Group 3, Control group: the third group was designated the comparison control group, which continued operating as usual with its bakery activities.

The interventions were implemented for at least 1 year. The investigators conducted unannounced random checks of all bakeries to assess the extent of adherence to the interventions. The ascertainment of use and implementation of interventions were conducted on two occasions during this period prior to the post-intervention dust and allergen measurements. During these visits, a checklist of compliance with intervention measures was completed. The checklist comprised questions on all intervention strategies covered during the training of workers, such as the use of divider oil, gentle handling and opening of flour bags (or shaking of bags), low dusting of dough tables, rubbing the dough table with flour, and correct use of lid on mixing tubs. The findings of these inspections were communicated to employers and bakery managers to reinforce intervention adherence during this period of implementation. This specific checklist of interventions was also completed at the time of dust and allergen measurements for individual workers wearing the personal dust samplers.

\section{Evaluation of intervention effectiveness}

A post-intervention survey was conducted to evaluate the effectiveness of the different intervention strategies in relation to the control group (see online supplementary figure S1). The postintervention assessments were conducted at the end of the 1 year implementation period. Exposure measurements across all three groups were conducted on 15 of the 18 bakeries originally evaluated at baseline, since three bakeries were lost to follow-up. Among these bakeries, a total of 128 workers were selected for personal environmental sampling ensuring that all five job titles were adequately represented in each bakery. The sampling was performed on all study subjects on two consecutive days as was done in the baseline exposure assessment study. $^{23}$

Flour dust and wheat allergen analysis and quantification

After weighing for inhalable flour dust particulate as described previously, ${ }^{23}$ the filters were prepared for immunological quantification. Extraction was done as described earlier ${ }^{24}$ and each sample was tested for wheat allergens by rabbit $\operatorname{IgG}$ inhibition $\mathrm{EIA}^{25}$ on two separate occasions. The arithmetic mean of the results was used as the wheat allergen concentration. Rye flour allergens were measured using a rabbit (New Zealand White) immunised with an allergenic rye seed extract ${ }^{26}$ and a two-sited assay developed after Protein G purification of the coating antibodies and antigen-affinity purification and biotinylation of the detection antibodies.

\section{Statistical analyses}

All statistical analyses were performed using Stata V.11 and SAS V.9.1 (SAS, 2002). Descriptive statistics were calculated stratified by job title and intervention group. PROC UNIVARIATE procedure in SAS was used to explore the distribution of the exposure data. All exposure data followed a skewed distribution, requiring the exposure data to be (natural) log transformed prior to statistical analysis. Mixed effects models were used to evaluate associations between specific controls and exposure measures in univariate analysis, using PROC MIXED from SAS System Software V.9.1 (SAS, 2002). Correlations between repeated measurements on the same individual were adjusted for by considering individual as a random effect. Observations from the same bakery may be correlated and we adjusted for this clustering by defining bakery as random effect. Mixed models were used to evaluate the effect of different control measures introduced both in separate models and the combined effect of all measures observed during the exposure assessment. The results are presented as post to pre ratios with 95\% CIs $(\exp (\beta \pm 1.96 \times \mathrm{SD} \beta)$. The exposure reduction was calculated as 1 -post to pre ratio. Analyses were performed overall, for example, for training, and per job where relevant and compound symmetric correlation was assumed for repeated measurements in the same subject. Furthermore, stepwise model building procedure was also used to identify determinants of flour dust reduction for inhalable flour dust and flour dust allergens. The stepwise model building procedure was conducted by systematically introducing individual intervention effects to the base mixed model with random effects and systematically adding additional intervention variables to the model to evaluate the significance of each additional effect to the base model, until a final model was developed. A $p$ value of 0.10 was used as criterion to determine the best model. Systematic model building as well as forward and backward model selection procedures was used.

\section{RESULTS}

Table 1 provides descriptive data for the exposure assessment both pre-intervention and post-intervention. The analysis was only conducted on groups for which we had exposure data preintervention and post-intervention due to a few bakeries in the control groups being lost to follow-up. A comparison of the overall intervention effect (baseline vs post-intervention) in 
Table 1 Comparison of changes in flour dust exposure particulate, wheat and rye allergen exposures pre-intervention and post-intervention in supermarket bakeries

\begin{tabular}{|c|c|c|c|c|c|c|c|c|c|c|c|}
\hline & \multicolumn{5}{|c|}{ Baseline } & \multicolumn{5}{|c|}{ Post-intervention } & \multirow{2}{*}{$\begin{array}{l}\text { Post to pre ratio } \\
(95 \% \mathrm{Cl})\end{array}$} \\
\hline & $\mathbf{n}$ & AM & GM & GSD & Range & $\mathbf{n}$ & AM & GM & GSD & Range & \\
\hline \multicolumn{12}{|c|}{ Inhalable flour dust $\left(\mathrm{mg} / \mathrm{m}^{3}\right)$} \\
\hline Total overall & 176 & 1.35 & 0.86 & 2.64 & $0.11-7.29$ & 208 & 0.64 & 0.43 & 2.56 & $0.01-4.07$ & 0.50 (0.40 to 0.63$)$ \\
\hline Lid and training & 70 & 1.25 & 0.85 & 2.44 & $0.12-6.57$ & 85 & 0.61 & 0.39 & 2.77 & $0.01-3.27$ & $0.48(0.33$ to 0.69$)$ \\
\hline Training only & 70 & 1.58 & 0.95 & 2.89 & $0.11-7.29$ & 78 & 0.70 & 0.47 & 2.43 & $0.07-4.07$ & $0.48(0.33$ to 0.71$)$ \\
\hline Control group & 36 & 1.11 & 0.74 & 2.54 & $0.11-5.25$ & 45 & 0.62 & 0.44 & 2.41 & $0.06-2.55$ & 0.59 (0.36 to 0.99$)$ \\
\hline \multicolumn{12}{|c|}{ Wheat allergen $\left(\mu \mathrm{g} / \mathrm{m}^{3}\right)$} \\
\hline Total overall & 176 & 14.49 & 7.07 & 4.21 & $0.00-69.64$ & 206 & 7.04 & 3.12 & 4.17 & $0.05-48.56$ & 0.45 (0.33 to 0.66$)$ \\
\hline Lid and training & 70 & 14.60 & 7.25 & 4.74 & $0.00-62.75$ & 85 & 6.08 & 3.11 & 3.81 & $0.06-35.28$ & 0.45 (0.26 to 0.76$)$ \\
\hline Training only & 70 & 17.21 & 8.52 & 3.96 & $0.24-69.64$ & 76 & 7.80 & 2.80 & 5.07 & $0.06-48.56$ & 0.33 (0.18 to 0.61$)$ \\
\hline Control group & 36 & 8.98 & 4.70 & 3.51 & $0.34-51.90$ & 45 & 7.57 & 3.79 & 3.45 & $0.51-42.25$ & 0.79 (0.39 to 1.60$)$ \\
\hline \multicolumn{12}{|l|}{ Rye allergen $\left(\mu \mathrm{g} / \mathrm{m}^{3}\right)$} \\
\hline Total overall & 176 & 5.67 & 2.57 & 4.43 & $0.00-31.08$ & 206 & 2.42 & 1.01 & 4.17 & $0.03-29.37$ & 0.40 (0.28 to 0.58$)$ \\
\hline Lid and training & 70 & 5.23 & 2.43 & 4.86 & $0.00-26.90$ & 85 & 2.16 & 0.90 & 4.14 & $0.03-29.37$ & 0.39 (0.22 to 0.69$)$ \\
\hline Training only & 70 & 7.02 & 3.13 & 4.39 & $0.07-31.08$ & 76 & 2.71 & 1.04 & 4.50 & $0.03-15.97$ & 0.32 (0.17 to 0.61$)$ \\
\hline Control group & 36 & 3.87 & 1.96 & 3.64 & $0.13-26.01$ & 45 & 2.42 & 1.21 & 3.72 & $0.06-10.20$ & 0.62 (0.29 to 1.32$)$ \\
\hline
\end{tabular}

The post-exposure to pre-exposure ratio has been calculated as $\exp (\beta)$ with $\beta$ being the regression coefficient for the specific variable in the mixed model with worker as random effect.

$A M$, arithmetic mean; GM, geometric mean; GSD, geometric SD; $n$, number of measurements in a group.

mixed model analysis revealed a 50\% decrease in inhalable dust exposures, $55 \%$ for wheat allergen and $60 \%$ for rye allergen levels (table 1). The overall intervention effect was similar across the two intervention groups. Surprisingly, the control group also showed a substantial reduction in exposure concentration, but to a lesser extent for allergen levels. However, the reduction $(55 \%-68 \%)$ in allergen levels among the intervention groups was almost double that of the control group (21\%-38\%). As a result, no significant difference in reduction was observed in intervention groups when compared with the control group. The reduction in exposure in control bakeries appeared to be associated with uptake of control measures following the introduction of the interventions (table 2). For example, bakers in the control group bakeries started using divider oil more frequently instead of flour (71\% vs 58\%), and handled bags more gently when opening them (79\% vs $33 \%)$ compared with intervention groups. The possible reason for the inadvertent introduction of intervention measures in the control group was due to the transfer of managers from the intervention group bakeries to the control group bakeries as occurs routinely in companies for reasons unrelated to the objectives of this study. After transfer, they introduced some of the new work practices in the control bakeries. As a result, we could not analyse the effects of interventions by comparing differences in trends in exposure between the different treatment groups and the controls. Alternatively, we explored the effect of changes in control measures on changes in exposure over time, across the different intervention groups.

The majority of workers in the intervention groups received training as described previously $(78 \%-88 \%)$. Those who did

Table 2 Inventory of control measures and level of compliance among bakers in all study groups preimplementation and postimplementation of intervention in supermarket bakeries

\begin{tabular}{|c|c|c|c|c|c|c|}
\hline \multirow[b]{3}{*}{ Control measures } & \multicolumn{6}{|c|}{ Adherence prevalence (\%) } \\
\hline & \multicolumn{2}{|l|}{ Group 1} & \multicolumn{2}{|l|}{ Group 2} & \multicolumn{2}{|l|}{ Group 3} \\
\hline & $\begin{array}{l}\text { Preimplementation } \\
(n=6)\end{array}$ & $\begin{array}{l}\text { Postimplementation } \\
(n=6)\end{array}$ & $\begin{array}{l}\text { Preimplementation } \\
(n=6)\end{array}$ & $\begin{array}{l}\text { Postimplementation } \\
(n=6)\end{array}$ & $\begin{array}{l}\text { Preimplementation } \\
(n=6)\end{array}$ & $\begin{array}{l}\text { Postimplementation } \\
(n=3)\end{array}$ \\
\hline Training conducted & 0 & 78 & 0 & 88 & NA & NA \\
\hline Lid installed onto mixer tubs & NA & 100 & NA & NA & NA & NA \\
\hline Lid used by bakers & NA & 49 & NA & NA & NA & NA \\
\hline Low dusting of dough tables & 0 & 86 & 0 & 58 & 0 & 71 \\
\hline Rubbing of dough table with flour & 0 & 67 & 0 & 42 & 0 & 43 \\
\hline $\begin{array}{l}\text { Divider oil for rubbing dough } \\
\text { tables }\end{array}$ & 21 & 58 & 0 & 45 & 0 & 71 \\
\hline $\begin{array}{l}\text { Gentle handling and opening of } \\
\text { flour bags }\end{array}$ & 0 & 33 & 0 & 32 & 0 & 79 \\
\hline \multicolumn{7}{|c|}{$\begin{array}{l}\text { Group 1=Lid for mixer tub and flour dust control training. } \\
\text { Group 2=Flour dust control training only. } \\
\text { Group 3=Control group. } \\
\text { Training was not provided to the control group, and lids were not present 'pre-intervention', and during intervention period, only group } 1 \text { had lids as part of the intervention strategy. } \\
\text { NA, not applicable. }\end{array}$} \\
\hline
\end{tabular}


Table 3 Personal inhalable flour dust particulate, wheat and rye allergen exposures pre-intervention and post-intervention in supermarket bakeries stratified by job title

\begin{tabular}{|c|c|c|c|c|c|c|c|c|c|c|c|c|c|c|}
\hline \multirow[b]{2}{*}{ Job title } & \multicolumn{6}{|c|}{ Baseline } & \multicolumn{7}{|c|}{ Post-intervention } & \multirow{2}{*}{$\begin{array}{l}\text { Post to pre ratio } \\
(95 \% \mathrm{Cl})\end{array}$} \\
\hline & k & $\mathbf{n}$ & AM & GM & GSD & Range & k & $\mathbf{n}$ & AM & GM & $\mathrm{GM}^{*}$ & GSD & Range & \\
\hline \multicolumn{15}{|c|}{ Inhalable flour dust $\left(\mathrm{mg} / \mathrm{m}^{3}\right)$} \\
\hline Bread baker & 49 & 98 & 1.89 & 1.39 & 2.23 & $0.25-7.29$ & 52 & 88 & 0.97 & 0.74 & 0.79 & 2.16 & $0.04-4.07$ & 0.53 (0.41 to 0.70$)$ \\
\hline Confectioner & 14 & 28 & 0.94 & 0.73 & 1.95 & $0.29-3.33$ & 34 & 57 & 0.51 & 0.41 & 0.43 & 2.06 & $0.05-1.68$ & 0.58 (0.40 to 0.85$)$ \\
\hline Baker supervisor & 5 & 9 & 0.82 & 0.61 & 2.24 & $0.20-2.67$ & 7 & 11 & 0.36 & 0.23 & 0.23 & 3.43 & $0.01-1.01$ & 0.36 (0.13 to 0.98$)$ \\
\hline Bakery manager & 5 & 9 & 0.87 & 0.60 & 2.58 & $0.12-2.47$ & 5 & 8 & 0.35 & 0.20 & 0.21 & 2.80 & $0.05-1.56$ & 0.33 (0.12 to 0.89$)$ \\
\hline Counterhand & 17 & 32 & 0.36 & 0.28 & 1.91 & $0.11-1.95$ & 30 & 44 & 0.29 & 0.22 & 0.23 & 2.09 & $0.03-1.23$ & 0.77 (0.54 to 1.10$)$ \\
\hline Overall & 90 & 176 & 1.35 & 0.86 & 2.64 & $0.11-7.29$ & 128 & 208 & 0.64 & 0.43 & 0.38 & 2.56 & $0.01-4.07$ & 0.50 (0.40 to 0.63$)$ \\
\hline \multicolumn{15}{|c|}{ Wheat allergen $\left(\mu \mathrm{g} / \mathrm{m}^{3}\right)$} \\
\hline Bread baker & 49 & 98 & 21.06 & 13.66 & 2.76 & $1.79-69.64$ & 52 & 87 & 11.84 & 7.51 & 10.03 & 2.89 & $0.18-48.56$ & 0.56 (0.39 to 0.81$)$ \\
\hline Confectioner & 14 & 28 & 8.48 & 6.76 & 1.98 & $1.71-30.66$ & 34 & 56 & 4.85 & 2.73 & 3.50 & 3.51 & $0.06-20.49$ & 0.41 (0.24 to 0.72$)$ \\
\hline Baker supervisor & 5 & 9 & 6.53 & 5.34 & 1.90 & $2.33-17.80$ & 7 & 11 & 4.16 & 1.77 & 2.49 & 3.81 & $0.35-18.40$ & 0.31 (0.09 to 1.08 ) \\
\hline Bakery manager & 5 & 9 & 10.72 & 4.91 & 4.55 & $0.32-40.28$ & 5 & 8 & 5.48 & 2.25 & 2.76 & 4.12 & $0.54-20.08$ & 0.47 (0.10 to 2.34$)$ \\
\hline Counterhand & 17 & 32 & 2.91 & 1.18 & 4.98 & $0.00-29.85$ & 30 & 44 & 1.32 & 0.79 & 1.07 & 2.86 & $0.06-10.63$ & 0.68 (0.37 to 1.25$)$ \\
\hline Overall & 90 & 176 & 14.49 & 7.07 & 4.21 & $0.00-69.64$ & 128 & 206 & 7.04 & 3.12 & 2.82 & 4.17 & $0.06-48.56$ & 0.45 (0.33 to 0.66$)$ \\
\hline \multicolumn{15}{|l|}{ Rye allergen $\left(\mu \mathrm{g} / \mathrm{m}^{3}\right)$} \\
\hline Bread baker & 49 & 98 & 8.41 & 5.17 & 2.96 & $0.30-31.08$ & 52 & 87 & 4.27 & 2.67 & 3.63 & 2.70 & $0.21-29.37$ & 0.53 (0.36 to 0.76$)$ \\
\hline Confectioner & 14 & 28 & 3.17 & 2.31 & 2.19 & $0.53-12.96$ & 34 & 56 & 1.54 & 0.91 & 1.18 & 3.03 & $0.09-6.48$ & 0.41 (0.23 to 0.73 ) \\
\hline Baker supervisor & 5 & 9 & 2.33 & 1.94 & 1.83 & $0.88-6.84$ & 7 & 11 & 1.22 & 0.60 & 0.80 & 3.60 & $0.13-3.77$ & 0.27 (0.08 to 0.91$)$ \\
\hline Bakery manager & 5 & 9 & 3.37 & 1.75 & 4.50 & $0.10-9.32$ & 5 & 8 & 1.62 & 0.42 & 0.49 & 5.86 & $0.03-8.80$ & 0.24 (0.04 to 1.69$)$ \\
\hline Counterhand & 17 & 32 & 1.03 & 0.40 & 4.75 & $0.00-10.92$ & 30 & 44 & 0.36 & 0.23 & 0.30 & 2.51 & $0.03-2.88$ & 0.57 (0.32 to 1.05$)$ \\
\hline Overall & 90 & 176 & 5.67 & 2.57 & 4.43 & $0.00-31.08$ & 128 & 206 & 2.42 & 1.01 & 0.78 & 4.17 & $0.03-29.37$ & 0.40 (0.28 to 0.58$)$ \\
\hline
\end{tabular}

The post-exposure to pre-exposure ratio has been calculated as $\exp (\beta)$ with $\beta$ being the regression coefficient for the specific variable in the mixed model with worker as random effect. $\mathrm{AM}$, arithmetic mean; GM, geometric mean; $\mathrm{GM}^{*}$, corrected for intervention group; GSD, geometric SD; $k$, number of workers sampled in an exposure group; $n$, number of measurements in a group.

not attend the training were on vacation, sick or not available. However, half $(51 \%)$ of the workers in group 1 were noncompliant and did not use the lid according to the guidelines, and none of the intervention groups used the industrial vacuum cleaner on a regular basis. Vacuums were not used effectively due to parts being missing as a result of poor maintenance, usage by other departments other than the bakery and lack of ongoing training of personnel.

A comparison of the reduction in exposure levels across all groups by job title is outlined in table 3 . The exposure percentage reduction in flour dust particulate (23\%-67\%), wheat (32\%-69\%) and rye allergen levels (43\%-76\%) was the highest for managers $(53 \%-76 \%)$, with bakers having a reduction in exposure levels of $44 \%-47 \%$, while the least reduction was observed for counterhands. The analysis was adjusted for the potential imbalanced job title distribution over groups, and showed no significant differences in the reduction levels after adjusting for intervention group.

Table 4 outlines the results of the identified control measures that were evaluated, corrected for intervention group. The effect of the use of the lid was estimated in the following groups: (1) for bakers in the post-intervention group who had lids and used them compared with bakers who did not use the lid but had a lid $(n=43)$; (2) for bakers who used lids compared with all other bakers who did not use a lid $(n=186)$; and (3) for bakers who had lids and used it compared with all bakers who did not have lids, and excluding those who had lids but did not use them $(n=164)$. The effect of use of divider oil was also analysed in two ways: (1) bakers who used divider oil compared with bakers who did not use divider oil $(n=186)$ and (2) bakers who used divider oil post-intervention compared with bakers who did not use divider oil and excluding those who used divider oil pre-intervention $(n=139)$. Correcting the estimates for the possible intervention group effect did not significantly impact on the $\beta$-estimates, and the group variable was not significant in any of the models. The use of a mixing tub with a lid $(\beta=-1.10 ; 67 \%)$, use divider oil instead of flour $(\beta=-0.99$; $63 \%)$ and rubbing the dough table $(\beta=-0.79 ; 55 \%)$ with flour, gentle handling and opening of bags $(\beta=-0.89 ; 59 \%)$ and low dusting practices $(\beta=-0.79 ; 55 \%)$ were all associated with significantly lower flour dust and allergen exposures. A composite variable that reflected the impact of the five combined interventions (divider oil, gentle handling and opening of flour bags, low dusting of dough tables, rubbing the dough table with flour, and correct use of lid on mixing tubs) was developed. The results demonstrate that the greatest reduction in flour dust $(80 \%)$ and wheat allergen (72\%) levels was achieved if workers employed a combination of all five control measures. A lower reduction in flour dust (48\%) and wheat allergen (61\%) was obtained if the lid was not installed and used on the mixer tub, and slightly lower reductions in flour dust $(45 \%)$ and wheat allergen (41\%) when using any one of the interventions. The results for rye allergens were essentially similar to the findings for wheat allergens and are therefore not presented.

\section{DISCUSSION}

To our knowledge, this is the first attempt to introduce a well designed intervention study in bakeries, evaluating the impact of localised specific intervention strategies. The study demonstrated a significant overall reduction in inhalable flour dust particulate $(50 \%)$, wheat $(56 \%)$ and rye $(61 \%)$ allergen exposure in bakeries from baseline. Stratifying the data for different jobs changed the overall effect by less than 5\%, suggesting no appreciable sampling effect. This is also the first study to demonstrate such 
Table 4 Effects of specific flour dust control reduction measures expressed as the ratio of post-intervention and pre-intervention exposure levels estimated using the mixed effects model of inhalable flour dust particulate and wheat allergen concentrations among bakers in supermarket bakeries taking into account repeated measurements at the same worker as random effect

\begin{tabular}{|c|c|c|c|c|c|}
\hline Model variables & $\mathbf{N}$ & Post to pre ratio & $95 \% \mathrm{Cl}$ & p Value & Per cent change \\
\hline \multicolumn{6}{|l|}{ Inhalable flour dust particulate (In) $\mathrm{mg} / \mathrm{m}^{3}$} \\
\hline \multicolumn{6}{|l|}{ Fixed effects of individual interventions } \\
\hline Lid used correctly by bakers & 164 & 0.33 & 0.19 to 0.56 & $<0.001$ & -67 \\
\hline Training instruction received & 311 & 0.46 & 0.35 to 0.61 & $<0.001$ & -54 \\
\hline Divider oil for rubbing work dough tables & 139 & 0.37 & 0.26 to 0.51 & $<0.001$ & -63 \\
\hline Rubbing of dough table with flour & 146 & 0.45 & 0.32 to 0.63 & $<0.001$ & -55 \\
\hline Low dusting of tables & 163 & 0.45 & 0.34 to 0.61 & $<0.001$ & -55 \\
\hline Gentle handling and opening of bags & 133 & 0.41 & 0.29 to 0.59 & $<0.001$ & -59 \\
\hline \multicolumn{6}{|l|}{ Combination of interventions } \\
\hline No intervention & 103 & 0 & & & \\
\hline Applying all five methods of control & 10 & 0.20 & 0.11 to 0.35 & 0.029 & -80 \\
\hline Applying only two methods of control & 7 & 0.52 & 0.26 to 1.01 & 0.208 & -48 \\
\hline Applying any one method of control & 66 & 0.55 & 0.41 to 0.73 & 0.057 & -45 \\
\hline \multicolumn{6}{|l|}{ Wheat allergen (In) $\mu \mathrm{g} / \mathrm{m}^{3}$} \\
\hline \multicolumn{6}{|l|}{ Fixed effects of individual interventions } \\
\hline Lid used correctly by bakers & 163 & 0.44 & 0.21 to 0.90 & 0.029 & -56 \\
\hline Training instruction received & 309 & 0.37 & 0.24 to 0.56 & $<0.001$ & -63 \\
\hline Divider oil for rubbing work dough tables & 138 & 0.43 & 0.29 to 0.65 & $<0.001$ & -57 \\
\hline Rubbing of dough table with flour & 145 & 0.48 & 0.32 to 0.73 & 0.001 & -52 \\
\hline Low dusting of tables & 162 & 0.47 & 0.32 to 0.69 & $<0.001$ & -53 \\
\hline Gentle handling and opening of bags & 133 & 0.50 & 0.30 to 0.81 & 0.007 & -50 \\
\hline \multicolumn{6}{|l|}{ Combination of interventions } \\
\hline No intervention & 103 & 0 & & & \\
\hline Applying all five methods of control & 10 & 0.28 & 0.14 to 0.58 & 0.074 & -72 \\
\hline Applying only two methods of control & 7 & 0.39 & 0.15 to 1.00 & 0.190 & -61 \\
\hline Applying any one method of control & 66 & 0.59 & 0.39 to 0.99 & 0.126 & -41 \\
\hline
\end{tabular}

The post-exposure to pre-exposure ratio has been calculated as $\exp (\beta)$ with $\beta$ being the regression coefficient for the specific intervention variable in the mixed model with worker as random effect.

a substantial reduction in exposure to flour dust and allergens in the workplace environment.

Studies designed to evaluate changes in exposure across time are also limited. In one of the most well-described studies in the wood processing industry, a group-randomised trial was used in which the intervention group received extensive intervention (written recommendations, technical assistance and worker training) while the control group only received written recommendation. ${ }^{22}$ However, a lower than expected reduction $(26 \%)$ was observed. These findings were ascribed to a short observation period, lack of intensive interventions and possible contamination among the control businesses through encounters with owners and workers from intervention businesses. A pragmatic intervention study in the Dutch bakery industry also found a small (2\%) reduction in average exposure to flour dust and allergens per year following large scale dissemination of an educational programme on exposure control, while other studies have shown reductions mainly at task level. ${ }^{18} 27$

In the current study, the intervention effect was similar across the two intervention groups, with the control group also showing a substantial reduction in exposure concentration. The changes in work practices observed in the control group and the consequent reduction in exposures in this group are indicative of a dilution effect and/or contamination among bakeries. This is in all probability due to the reported movement of managers between bakeries (from intervention group bakeries to control group bakeries), also a result of promotion or job rotation; a greater awareness of risks of flour dust as a result of being in the study; and to a lesser extent encounters of control group workers with workers from intervention bakeries during the period of the intervention. This was evident in the evaluation of the changes and uptake of control measures following the introduction of the interventions. Notably, changes in work practices were also observed in the control group. For example, bakers in the control group bakeries started using divider oil more frequently instead of flour ( $71 \%$ vs $58 \%$ ), and handled bags more gently when opening them (79\% vs 33\%). While differences in baseline exposures were observed between the control and intervention groups could be attributed to the random variation for dust particulate levels, the substantially larger variation for allergens is not easily explained. This may have complicated the stratified analysis for the intervention effect over and above the effect caused by the contamination. However, it is unlikely that this impacted on the overall conclusions based on the pre and post total dust particulate comparison. Overall, it is also probable that participation in such a study may have led to the adoption of safer work practices even in the absence of targeted interventions to reduce exposure.

In this study, the change across job categories showed a reduction in exposure among bakers of $45 \%$, while a much greater reduction was observed among managers in these bakeries. These changes could be attributed to the reduced active involvement of managers in the work processes over time due to increased administrative responsibilities, resulting in less time being spent in the bakery section of the supermarket. Although the reduction in exposures differed by job title, the interventions 
were mainly directed at bread bakers, since this group of workers were involved in tasks with the highest flour dust exposure.

Bakeries that substituted flour with divider oil showed clear reductions in flour dust exposures. Studies by Burstyn et al ${ }^{28} 29$ also showed a 28 -fold decrease in flour dust exposure when substituting dusting flour with divider oil, while Meijster et $a l^{30}$ found a more modest reduction in exposure when substitutes like divider oil and dust-free flour were used. However, in the current study, the stepwise model building analysis showed that process divider oil in the presence of other exposure determinants was not found to be a significant exposure determinant contrary to the other studies. ${ }^{28}$ In this current study, using the mixing tub lid in the stepwise models clearly had the largest effect on baker's exposure as its use was less variable than divider oil due to it being a relatively fixed engineering control measure. Possible explanations for this observation may be attributed to the fact that divider oil is not used during the entire shift or short-term tasks such as the production of 'Portuguese' rolls or 'Italian' breads that produce high flour dust exposures, which may dampen the effect of divider oil. Furthermore, studies in the Netherlands have also shown a small reduction in flour dust levels with the elimination of dusting flour since substitution was often only partial. ${ }^{30}$ In almost all cases, substitutes were introduced while dusting flour was still used as part of the production process. However, in instances where sprinkling flour was totally eliminated, substantial reductions in exposure were observed. Studies in other sectors have also shown less than substantial reduction in exposures due to the substitution of dusty products with less dusty materials. $^{31}$

In this study, the demonstrated effectiveness of the mixing tub lid is consistent with large scale Dutch studies that show control measures introduced during the weighing of ingredients, especially by limiting the use of bagged flour products and the enclosure of silos (when dumping flour), strongly decrease exposure. ${ }^{30}$ The important strength of this current study is that the lid was specifically designed so that it could be easily maintained and widely accessible for use in all bakeries to promote future compliance with and long-term sustainability of the intervention beyond the study period.

As expected, workers who continued to shake bags during dough processing and employed high dusting instead of rubbing with flour showed an increase in exposures. This clearly demonstrated that work practices and worker behaviour during tasks have a great impact on exposure. This is a common finding of previous studies on exposure control and interventions, which point to the importance of worker behaviour, skills and hygiene on exposure. ${ }^{22} 32$

Few studies have evaluated the specific impact of training in bakeries. A sector-wide intervention programme in Dutch bakeries aimed primarily at education of workers showed a rather limited effect on exposure levels. ${ }^{18}$ The authors concluded that although workers' knowledge on the risk of flour dust exposure improved, this resulted in change in work practices only to a limited extent. In this current study, the training focused on much more than the use of engineering controls such as the lid for the mixer tub. It also strongly focused on modification of certain behaviours to encourage gentle handling and opening of flour bags and careful sprinkling of flour on dough tables, and therefore had its own impact irrespective of the availability of the mixer tub lid. The changes in work processes supplemented by technical aids emphasised during training were associated with a substantial reduction in flour dust exposures.
Furthermore, using either a crude measure of self-reported training or a more precise indicator of actual changes in work processes consistently showed a reduction in exposures. In this current study, training of workers on its own was associated with a $54 \%$ reduction in flour dust levels. A recent review on the effectiveness of occupational health and safety training confirms that training promotes safer practices among workers and recommends that workplaces continue to deliver Occupational Health and Safety (OHS) training as part of a larger programme. It cautions however that training alone will not necessarily prevent injuries and illnesses. ${ }^{33}$ A strength of the current study is that the specific flour dust control training programme that was developed has subsequently been incorporated into the overall bakery training programme. This will further enhance future compliance with and sustainability of the intervention over time.

The overall findings of the study demonstrate that the contribution of specific task-related control measures has a major impact at an individual level as well as on the broader overall population exposures. Since average exposure is likely to be caused mainly by peaks, important exposure determinants were identified that are very likely associated with these peaks. It is these determinants that were prioritised for the interventions used in this study that showed a substantial effect on average exposure. It is likely that this substantially decreased the number and/or intensity of peak exposures but probably did not address all these sources. Interventions in bakeries should therefore cover a range of tasks and control measures to have substantial impact on the population exposure distribution. The study also demonstrated that a multi-faceted approach of specific training accompanied by technical aids on correct flour handling and practices substantially complements other higher level control measures in reducing flour dust and allergen levels. This is similar to a message that has been emerging from other Institute for Work \& Health systematic reviews that multi-component programmes are the key to effective prevention. ${ }^{33}$

One of the limitations of the study was the inability to resample the same workers who were previously assessed in the baseline exposure assessment survey due to turnover movement of workers between different jobs and turnover of workers between bakeries. It was also not possible to completely separate the effect of individual control measures since they were highly correlated. Furthermore, the changes in work practices observed in the control group and the consequent reduction in exposures in this group are indicative of a dilution effect and/or contamination among bakeries. However, irrespective of these limitations, this study was able to show a significant intervention effect of the different strategies implemented. Due to the relatively short (1 year) period of follow-up, the study could not identify if the reduced levels were sustainable in the longer term.

\section{CONCLUSIONS}

This study has demonstrated that targeted interventions directed at individual workers within an identified high-risk population (eg, bread bakers) can have a substantial effect on flour dust exposures in bakeries. Further studies of this cohort are planned to determine the long-term impact of the intervention strategies in sustained reduction of exposures and improved health outcomes in this group of bakers.

Acknowledgements We would like to acknowledge the special contribution of the following individuals and institutions. Dr Gert Doekes and Jack Spithoven of the Institute for Risk Assessment Sciences, Utrecht University, Utrecht, The Netherlands for wheat and fungal $\alpha$-amylase analysis of airborne dust samples. Dr Tanusha Singh, National Institute for Occupational Health, for facilitating dust sample 
analysis, and research nurse assistant Dawn Venter from the Centre for Occupational and Environmental Health Research Unit for the fieldwork. The contents of our report are solely the responsibility of the authors and do not necessarily reflect the official views of these agencies. We would also like to acknowledge the staff and employees of the bakeries that participated in this study.

Contributors MFJ was responsible for the overall study design, conceptualising and ensuring the development of the intervention as well as overseeing preparation of the manuscript. RB was responsible for implementing the fieldwork, conducting the data analysis and preparing the manuscript. Advanced statistical analysis and support were provided by TM and DH who also contributed towards the manuscript. IS was responsible for the allergen analysis and reviewing the manuscript.

Funding Funding support was provided through research scholarship grants from the Center for Asthma in the Workplace (Montreal, Canada), Medical Research Council (Republic of South Africa), the National Research Foundation FA2006040700028 (Republic of South Africa), the Fogarty International Centre (Bethesda, Maryland, USA), the Allergy Society of South Africa (Cape Town) and University of Cape Town Research Committee (Cape Town) and the baking industry (Cape Town)

\section{Competing interests None.}

Patient consent Obtained

Ethics approval University of Cape Town, Research Ethics Committee.

Provenance and peer review Not commissioned; externally peer reviewed.

\section{REFERENCES}

1 Malo JL, Chan-Yeung M, Bernstein DI. Asthma in the workplace. 4th edn. CRC Press, 2013.

2 Houba R, Heederik D, Doekes G. Wheat sensitisation and work-related symptoms in the baking industry are preventable. An epidemiologic study. Am J Resp Crit Care Med 1998;158:1499-503.

3 Cullinan $\mathrm{P}$, Lowson D, Nieuwenhuiisen MJ, et al. Work-related symptoms, sensitisation, and estimated exposure in workers not previously exposed to flour. Occup Environ Med 1994;51:579-83.

4 Droste J, Myny K, Van Sprudel M, et al. Allergic sensitization, symptoms, and lung function among bakery workers as compared with a non-exposed work population. J Occup Environ Med 2003:45:648-55.

5 Brant A, Berriman J, Sharp C, et al. The changing distribution of occupational asthma: a survey of supermarket bakery workers. Eur Respir J 2005;25:303-8.

6 Brisman J. Baker's asthma. Occup Environ Med 2002;59:498-502.

7 Baatjies R, Lopata AL, Sander I, et al. Determinants of asthma phenotypes in supermarket bakery workers. Eur Respir J 2009;34:825-33.

8 Vandenplas 0, Jamart J, Delwiche JP, et al. Occupational asthma caused by natura rubber latex: outcome according to cessation or reduction of exposure. J Allergy Clin Immunol 2002;109:125-30.

9 Brant A, Zekveld C, Welch J, et al. The prognosis of occupational asthma due to detergent enzymes: clinical, immunological and employment outcomes. Clin Exp Allergy 2006;36:483-8.

10 Houba R, Heederik DJ, Doekes G, et al. Exposure-sensitisation relationship for alpha-amylase allergens in the baking industry. Am J Respir Crit Care Med 1996;154:130-6

11 Hur G, Koh D, Kim H, et al. Prevalence of work-related symptoms and serum-specific antibodies to wheat flour in exposed workers in the bakery industry. Respir Med 2008:102:548-55.

12 Nieuwenhuijsen MJ, Heederik D, Doekes G, et al. Exposure-response relations of alpha-amylase sensitisation in British bakeries and flour mills. Occup Environ Med 1999:56:197-201.
13 Meijster T, Warren N, Heederik D, et al. What is the best strategy to reduce the burden of occupational asthma and allergy in bakers? Occup Environ Med 2011;68:176-82.

14 de Groene GJ, Pal TM, Beach J, et al. Workplace interventions for treatment of occupational asthma: a Cochrane systematic review. Cochrane Database Syst Rev 2011;(5):CD006308

15 Heederik D, Henneberger PK, Redlich CA; ERS Task Force on the Management of Work-related Asthma. Primary prevention: exposure reduction, skin exposure and respiratory protection. Eur Respir Rev 2012;21:112-24.

16 Bakerly ND, Moore VC, Vellore AD, et al. Fifteen-year trends in occupational asthma: data from the Shield surveillance scheme. Occup Med (Lond) 2008:58:169-74.

17 Creely KS, Cowie H, Van Tongeren M, et al. Trends in inhalation exposure-a review of the data in the published scientific literature. Ann Occup Hyg 2007:51:665-78.

18 Meijster T, Tielemans E, Heederik D. Effect of an intervention aimed at reducing the risk of allergic respiratory disease in bakers: change in flour dust and fungal alpha-amylase levels. Occup Environ Med 2009;66:543-9.

19 Jacobs JH, Meijster T, Meijer E, et al. Wheat allergen exposure and the prevalence of work-related sensitization and allergy in bakery workers. Allergy 2008:63:1597-604.

20 Heederik D, van Rooy F. Exposure assessment should be integrated in studies on the prevention and management of occupational asthma. Occup Environ Med 2008;65:149-50.

21 Tarlo S, Liss GM. Prevention of occupational asthma. Curr Allergy Asthma Rep 2010;10:278-86

22 Lazovich D, Parker DL, Brosseau LM, et al. Effectiveness of a worksite intervention to reduce an occupational exposure: the Minnesota wood dust study. Am J Public Health 2002;92:1498-505.

23 Baatjies R, Meijster T, Lopata AL, et al. Exposure to flour dust in South African supermarket bakeries: Modelling of baseline measurements of an intervention study. Ann Occup Hyg 2010;54:309-18.

24 Schram D, Doekes G, Boeve M, et al. PARSIFAL Study Group. Bacterial and fungal components in house dust of farm children, Rudolf Steiner school children and reference children-the PARSIFAL Study. Allergy 2005;60:611-18.

25 Bogdanovic J, Wouters IM, Sander I, et al. Airborne exposure to wheat allergens: measurement by human IgG4 and rabbit IgG immunoassays. Clin Exp Allergy 2006;36:1168-75

26 Sander I, Kespohl S, Merget R, et al. A new method to bind allergens for the measurement of specific IgE antibodies. Int Arch Allergy Immunol 2005;136:39-44.

27 Meijster T, Tielemans E, Schinkel J, et al. Evaluation of peak exposures in the dutch flour processing industry: implications for intervention strategies. Ann Occup Hyg 2008;52:587-96

28 Burstyn I, Teschke K, Kennedy SM. Exposure levels and determinants of inhalable dust exposure in bakeries. Ann Occup Hyg 1997;41:609-24.

29 Burstyn I, Teschke K, Bartlett K, et al. Determinants of wheat antigen and fungal alpha-amylase exposure in bakeries. Am Ind Hyg Assoc J 1998;59:313-20.

30 Meijster T, Tielemans E, de Pater N, et al. Modelling exposure in flour processing sectors in The Netherlands: a baseline measurement in the context of an intervention program. Ann Occup Hyg 2007;51:293-304.

31 Vermeulen R, de Hartog J, Swuste P, et al. Trends in exposure to inhalable particulate and dermal contamination in the rubber manufacturing industry: effectiveness of control measures implemented over a nine-year period. Ann Occup Hyg 2000;44:343-54

32 Elms J, Robinson E, Rahman $\mathrm{S}$, et al. Exposure to flour dust in UK bakeries: current use of control measures. Ann Occup Hyg 2005;49:85-91.

33 Robson LS, Stephenson CM, Schulte PA, et al. A systematic review of the effectiveness of occupational health and safety training. Scand J Work Environ Health 2012;38:193-208. 